Handelsabkommen

\section{EU-Mercosur auf der Kippe}

Die Verhandlungen über ein Handelsabkommen zwischen der Europäischen Union und dem gemeinsamen Markt Südamerikas (Mercosur) dauern fast so lange wie der Mercosur existiert. Nach der Gründung des Mercosur 1991 begannen 1995 erste Gespräche zwischen den beiden Handelsblöcken, ab 2000 dann mit offiziellem Verhandlungsmandat von EU-Seite. Im Juni 2019 hatte man sich schließlich auf den Entwurf eines Vertragstextes geeinigt. Damit aus diesem „Agreement in Principle“ ein gültiges internationales Abkommen werden kann, muss es auf europäischer Seite durch das Parlament und durch die Mitgliedstaaten ratifiziert werden. Das kann dauern. Das Handelsabkommen der EU mit Kanada, dessen endgültiger Vertragstext 2016 unterzeichnet wurde, haben bisher nur knapp die Hälfte der Mitgliedstaaten ratifiziert - unter anderem auch Großbritannien (November 2018), aber noch nicht Deutschland. Dass es mit dem Mercosur-Abkommen einfacher und schneller geht, war schon immer unwahrscheinlich, doch nun hat das europäische Parlament sich gegen eine Ratifizierung in seiner jetzigen Form ausgesprochen. Wenn sich die Verhandlungsparteien auf beiden Seiten jetzt nicht bewegen, dann sind die Ergebnisse 20-jähriger Verhandlungen Makulatur.

Das Europäische Parlament lehnt das Handelsabkommen mit dem Mercosur nicht grundsätzlich ab, sondern spricht inm durchaus großes wirtschaftliches Potenzial zu. Ausdrücklich erwähnt werden die Vertiefung der strategischen Partnerschaft mit Lateinamerika, die Diversifizierung der Lieferketten für die europäische Wirtschaft, die Schaffung eines gemeinsamen Wirtschaftsraums für 800 Mio. Menschen und vieles mehr. Der Widerstand gegen das Abkommen speist sich vor allem aus umweltpolitischen Erwägungen. So wird z.B. eingewendet, das Mercosur-Abkommen werde zu einer verstärkten Entwaldung im Amazonasgebiet und zu Millionen von zusätzlichen Tonnen $\mathrm{CO}_{2}$-Emissionen führen. Das Parlament fordert nun eine Neuverhandlung des Abkommens mit dem Ziel, dieses mit dem European Green Deal in Einklang zu bringen. Das ist der umwelt- und wachstumspolitische Aktionsplan, den der Europäische Rat auf Betreiben der Kommissionspräsidentin Ursula von der Leyen im Dezember 2019 beschlossen und dem das Parlament im Januar 2020 ausdrücklich zugestimmt hat. Das Parlament wirft damit der Kommission und dem Rat den Fehdehandschuh hin und verlangt, dass diese die Umset-

(C) Der/die Autor(en) 2020. Open Access: Dieser Artikel wird unter der Creative Commons Namensnennung 4.0 International Lizenz (https:// creativecommons.org/licenses/by/4.0/deed.de) veröffentlicht.

Open Access wird durch die ZBW - Leibniz-Informationszentrum Wirtschaft gefördert. zung der gemeinsamen Ziele ernst nehmen und es nicht bei vagen Absichtserklärungen bewenden lassen. Die Fraktion der Grünen war dabei die treibende Kraft, doch es ist bezeichnend, dass dies auch andere Parteien breit unterstützten. Das Parlament hat hier tatsächlich einen wirksamen Hebel: Ohne seine Zustimmung kann das Handelsabkommen nicht zustande kommen. Man kann dies durchaus als Machtdemonstration einer europäischen Institution ansehen, die in der Vergangenheit gedemütigt wurde, so z. B. im Auswahlprozess für die neue EU-Kommissionspräsidentin.

Wie geht es jetzt weiter? Das Handelsabkommen mit dem Mercosur steht noch immer auf der Agenda. Zu viele Stakeholder auf beiden Seiten haben ein Interesse daran. Insbesondere Brasilien, das wegen seiner Rodungspolitik am Amazonas kritisiert wird, ist unter Druck, sich zu bewegen. Das internationale Umfeld ist günstig. Der designierte USPräsident Joseph Biden hat die Rückkehr in das Pariser Klimaabkommen signalisiert. Statt auf Schutzzölle, Drohungen und Handelskrieg setzt er auf Multilateralismus und Kooperation mit Europa. Auch er hat einen Green New Deal angekündigt, der sich in seinen groben Umrissen vom European Green Deal wenig unterscheidet. Die Bolsonaro-Regierung in Brasilien - selbst wenn sie Bestand haben sollte - dürfte es unter Biden erheblich schwerer haben, ihre katastrophale und zynische Umweltpolitik weiterzuführen. Diese und andere Gründe sprechen dafür, dass sich das MercosurAbkommen retten lässt. Doch auch die Europäische Union muss sich bewegen. Prinzipienfestigkeit im Umweltschutz und bei Menschenrechten ist wichtig, doch ohne Flexibilität und Handlungsfähigkeit kann die EU ihren Anspruch auf eine Rolle als eigenständige Akteurin zwischen den Supermächten USA und China nicht einlösen.

Die Welthandelsordnung der WTO, noch vor Kurzem Lieblingsziel der Globalisierungskritiker, erscheint im Rückblick als beschauliche Idylle. Schon jetzt erlaubt die Realität des Welthandels den Blick in eine Zukunft, in der internationale Handelskriege und die unverblümte Ausübung nackter Wirtschaftsmacht Realität wären. Wenn Handelsabkommen mit einzelnen Ländern oder Wirtschaftsblöcken immer schwieriger werden, dann bleibt am Ende nur die Wahl zwischen der unverbindlichen Welthandelsordnung der WTO und einem Welthandel, in dem das Recht des Stärkeren gilt. Dies kann nicht im Interesse der Europäischen Union sein. Als weltweit größter Wirtschaftsraum muss sie sich aktiv in die Gestaltung der Welthandelsordnung einbringen. Das Handelsabkommen mit dem Mercosur und das Investitionsabkommen mit China (CAl), bei dem derzeit der Text verhandelt wird, wären dafür wichtige Bausteine. Die Europäische Union sollte sich dabei nicht selbst im Wege stehen.

Martin Klein

Martin-Luther-Universität Halle-Wittenberg martin.klein@wiwi.uni-halle.de 